\title{
Pemanfaatan Film Animasi Sebagai Media Pembelajaran Anak Berbasis Flashmx
}

\author{
Supriyadi \\ Universitas Nusa Mandiri \\ e-mail :spy2adi@gmail.com
}

Diterima : 2021-01-02

Direvisi : 2021-02-20

Diterima : 2021-08-01

\begin{abstract}
Entertainment-based education can be done by teachers and parents to design learning materials about soft skills in children such as helping children. The usefulness of this animated film, has a function as an entertainment tool and as a learning medium for children so that children do not feel bored and are able to provide freshness because of the entertainment element. Of the many animated films that are shown, not many teach about something that contains the meaning of goodness, for example the attitude of helping each other. After making this film, it shows that this film has an interesting storyline and is worthy to be watched by children aged 2-8 years and contains educational values both morally and religiously and can entertain children. Children always want to help people who are having difficulties, namely by helping everyone so that they can help ease the burden of suffering from others and get a reward from the creator. The making of this animation using Macromedia Flash MX software by adding a mixture of visual effects in each scene to make it more interesting and the picture clearer.
\end{abstract}

Keywords: Animation, Media, Graphic, Edutainment

\section{PENDAHULUAN}

Perkembangan teknologi media dan komputer memiliki fungsi sebagai alat penghibur dan pendidikan, salah satu yang sangat berperan adalah untuk membantu proses terciptanya media audio visual dalam bentuk film animasi (Bekti Wulansari, 2019).

Film animasi merupakan film dari proses pengolahan gambar diam menjadi gambar bergerak. Pada perkembangannya terdapat 2 proses pembuatan film animasi ialah secara konvensional dan digital. Tom Cardone seseorang animator yang menciptakan animasi Hercules mengakui proses pembuatan animasi digita lebih cepat dibanding dengan proses konvensional, untuk prose secara konvensional memerlukan waktu 2 hari sebaliknya secara digital cuma memerlukan waktu antara 30- 45 menit. Untuk pembuatan secara konvensional dalam pembuatan gambar lebih mudah serta gambar yang dihasilkan sesuai dengan yang di konsepkan. Konsep untuk proses dalam pembuatan film animasi ini hendak digunakan tata cara 2D Hybrid Animation ialah penggabungan antara gambar manual diatas kertas, di scan serta ditransfer ke pc setelah itu di konversi jadi gambar digital. (Herliyani, 2014)
Film animasi ialah tontonan yang sangat disukai oleh kanak- kanak. Dari penayangan film animasi tersebut manfaat yang diperoleh untuk anak ialah imajinasi yang sangat diperlukan serta baik buat pertumbuhan anak. Tetapi tidak cuma sisi positif yang dapat diambil oleh anak dari tayangan tersebut, ada juga sisi negatifnya dari penayangannya, misalnya sikap kurang baik yang ditampilkan dalam film animasi yang dilihatnya semacam kebohongan, kenakalan, serta sikap tidak terpuji yang lain sehingga memberikan contoh yang tidak baik terhadap pertumbuhan anak. (Subakti, 2008).

Suatu riset yang dilakukan stasiun Televisi swasta di Indonesia, antara lain Global TV, Indosiar, serta ANTV dihasilkan prosentase siaran yang memiliki tayangan kekerasan, seksisme, dan mistis sebesar $85 \%$. Cuma $15 \%$ siaran yang memiliki nilai tayangan pembelajaran pada anak, sebagai contoh tayangan Dora, Unyil, serta si Bolang. Contoh tayangan kekerasan yang timbul dalam film tersebut yang menimbulkan efek kekerasan dalam wujud perkelahian, antara lain Naruto, Power Rangers, dan Spongebobs dimana tiap episodenya senantiasa diwarnai dengan adegan perkelahian. Demikian pula dengan tayangan 
adegan non raga, sebagai contoh mengejek diantara tokoh, membulli, kelicikan, pendendam serta iri. (Dwi Susanti, 2009).

Frekuensi serta lama menyaksikan tv pada kanak- kanak, jauh lebih besar dibanding frekuensi mereka belajar. Efek dari media untuk anak bersosialisasi sebagian besar dipengaruhi oleh isi siaran tv daripada pembelajaran dari guru ataupun orang tua mereka. Dari sekian banyak film kartun ataupun animasi yang disiarkan di televisi, belum banyak film yang mengarahkan tentang suatu yang memiliki arti pendidikan, misalnya tentang tolong menolong. Mayoritas film animasi ialah film buatan luar negara semacam Jepang, Amerika, serta lainlain yang umumnya yang hanya menggambarkan tentang petualangan, perang, perselisihan, imajinasi, serta lain- lain. (Darwanto Sastro, 2005).

Bersumber pada hasil wawancara dengan sebagian guru PAUD ataupun TK bisa disimpulkan, kalau ada anak-anak yang suka menghasut teman lainnya saat dia menganggap tidak cocok. Dia menghasut teman lainnya supaya tidak lagi berteman dengan teman yang tidak ia sukai. Dilihat dari permasalahan diatas, bila ditilik dari pertumbuhan religious anak sangatlah sedikit. Butuh terdapatnya penanaman kepribadian tentang nilai-nilai keagamaan yang tinggi pada anak, sebab pada umur tersebut kepribadian anak lebih cenderung bisa dirubah dibanding kepribadian pada orang dewasa sehingga kepribadian religious pada anak bisa ditingkatkan. Penting diterapkan dalam penanaman kepribadian yang baik semoga film animasi yang penulis buat ini dapat bermafaat untuk perkembangan anak Indonesia.

\section{METODELOGI PENELITIAN}

Penelitian yang berjudul "Implementasi Tweening Animation yang ditulis oleh Nurjanah berisi tentang pemanfaatan teknik animasi tweening dalam pembuatan film kartun. Dalam film ini pembuatan karakter menggunakan software Adobe Flash CS3. Film animasi yang dihasilkan terlihat kaku dan kurang menarik. (Nurjanah, 2009).

Dari hasil penelitian yang dilakukan oleh Gerihandito menghasilkan "Teknik Tweening Dalam Pembuatan Film Kod_Dok". Pembuatan objek dilakukan dengan cara menggambar di kertas setelah itu di scan. Proses pewarnaan menggunakan software
Macromedia Flash MX. Film yang berdurasi kurang dari 1 menit ini hanya menghasilkan animasi loncatan kodok dan nyamuk. Selain itu dalam pembuatan gambar yang sama harus melakukannya berulang-ulang untuk adegan yang berbeda. (Yoko Gerihandito, 2006)

\section{Multimedia Film Dan Animasi}

Film biasa dipakai buat merekam sesuatu kondisi ataupun mengemukakan suatu. Film dipakai buat penuhi sesuatu kebutuhan universal, ialah mengkomunikasikan sesuatu gagasan, pesan ataupun realitas. Berdasarkan pengaruh dan manfaatnya, media film saat ini merupakan media audio visual yang sangat digemari oleh seluruh lapiran masyarakat ditonton sehingga segala sesuatunya banyak hal yang dapat ditayangkan didalam paket penayangannya. (Iwan Binanto, 2010).

Film animasi berasal dari 2 disiplin ilmu, ialah film yang berakar pada bidang audio visual serta animasi yang berakar pada bidang objek grafis. Animasi merupakan hasil proses dimana objek- objek yang dijadikan ataupun divisualisasikan agar nampak hidup. Objek digerakkan lewat gerakan sedikit demi sedikit sehingga proses gerakannya menjadi lebih terkesan hidup. (Ruslan, 2016).

Dalam dunia penyiaran terdapat syarat dalam penentuan resolusi animasi. Resolusi tersebut mempengaruhi pada frame per secondnya, bagi NTSC (National televition Standard Comitee) dimensi dasar yang digunakan antar frame per second ialah 24 frame per second (24fps).

\section{HASIL DAN PEMBAHASAN}

Pada rancangan dan produksi animasi kali ini, dengan menggunakan teknik animasi 2 dimensi. Film animasi tersebut berisi tentang keseharian seseorang anak yang tetap mengamalkan sikap tolong menolong dalam kehidupan sehari-hari. Dalam film animasi tersebut diiringi musik serta suara ataupun audio supaya memudahkan serta memperjelas dalam menguasai isi cerita dan menarik atensi kanak- kanak.

Format dari proses pembuatan animasi yang dibuat diharapkan dapat mampu untuk: a. Menampilkan film animasi yang mempunyai pesan moral tinggi.

b. Menampilkan imajinasi untuk anak. c. Menampilkan karakter yang sesuai dengan cerita yang diangkat. 


\section{d. Proses animasi dilakukan dengan teknik} animasi 2 dimensi.

Agar proses pembuatan film animasi menjadi mudah maka gunakan alur kerja yang. Namun semudah apapun proses yang terjadi, maka harus melewati urutan proses yang secara sederhana terdiri atas: Ide, Desain Produksi, Pra Produksi, Produksi, Paska Produksi, dan Publikasi. (Widagdo, 2007).

Alur proses (pra produksi) dalam pembuatan film animasi meliputi:

\section{Menentukan ide}

Ide merupakan keseluruhan pengalaman, pengamatan \& analisis kita terhadap realitas di sekitar kita. Bahan-bahan tersebut berkembang dari waktu ke waktu. Dibutuhkan waktu dalam proses pemilahan dalam pengembangan ide yang intensif.

Tema ini muncul terjadi dalam kehidupan sehari-hari bahwa anak-anak lebih suka asik dengan kegiatannya masing-masing tanpa melihat disekelilingnya. Perlu adanya informasi kepada anak-anak untuk bersikap rendah hati dilingkungan sekitarnya.

\section{Tema}

Tema yang diambil pada film animasi "Si Iko episode Penyesalan" adalah tentang seorang anak laki-laki dalam keluarga petani kecil yang sangat sederhana. Namanya Iko, anak laki-laki dari keluarga tersebut berubah sikap menjadi anak yang membantah kepada orang tuanya akibat ejekan dari teman-temannya. Suatu ketika ayah Iko jatuh sakit akibat sikap buruk iko. Lalu iko pun menyesali perbuatannya dan meminta maaf kepada orang tuanya.

Selain sebagai hiburan, program ini juga mengedukasi penonton dengan memberikan pesan moral yang terdapat dalam film yaitu:

1. Harus selalu menghormati orang tua, karena bagaimanapun tanpa mereka kita tidak ada di dunia.

2. Tidak boleh saling mengejek teman yang berkekurangan maupun berbeda dengan kita.

3. Tidak boleh menghasut tanpa ada bukti yang jelas.

4. Sebagai sesama teman harus saling memaafkan.

\section{Naskah}

Dalam pembuatan karya animasi ini, penulis melampirkan sinopsis dari animasi ini, yaitu: Di suatu Desa yang asri, hiduplah keluarga yang terdiri dari seorang Ayah, Ibu, dan seorang Anak laki-laki. Keluarga tersebut adalah keluarga kecil yang sangat sederhana. Namun Iko, anak laki-laki dari keluarga tersebut berubah sikap menjadi anak yang membantah orang tuanya akibat ejekan dari temantemannya. Suatu ketika ayah Iko jatuh sakit akibat sikap buruk iko. Lalu iko pun menyesali perbuatannya dan meminta maaf kepada orang tuanya. Yang mendatangkan kebahagiaan baru untuk iko.

Film animasi Si iko episode "Penyesalan" bertemakan cerita kehidupan seorang anak laki - laki dari sebuah keluarga petani sederhana. Awalnya iko seorang anak baik dan periang. Namun terjadi konflik dengan temannya karena sang anak malu sering diejek oleh temannya. Iko berubah menjadi anak yang pemurung dan memberontak dengan orang tuanya. Yang mengakibatkan ayahnya jatuh sakit.

Lalu iko pergi kesebuah pertokoan dan timbul konflik batin lantaran iko ingin memiliki sebuah sepatu untuk mengganti sepatunya yang rusak namun iko tidak memiliki uang. Ditengah lamunan nakal iko teringat akan kejadian saat ayahnya jatuh sakit akibat perkataanya. Akhirnya iko memutuskan untuk pulang dan meminta maaf kepada kedua orangtuanya. Beberapa hari kemudian, ayah membelikan iko sepatu baru yang sama dengan yang waktu itu iko lihat dipertokoan. Dan teman-teman yang mengejek iko juga meminta maaf kepadanya.

Sikap membuly itu tidak baik. Karena dapat merugikan korban dan orang sekitarnya. Selain itu juga mengajarkan untuk tidak mencuri karena pasti menimbulkan kerugian untuk diri sendiri maupun orang sekitar terutama keluarga. Dan karakter yang memerankan juga unik dan terinspirasi dari mainan anak kecil.

\section{Character Development}

\section{Karakter utama}

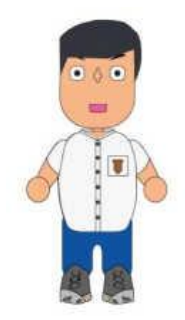

Gambar 1. Karakter Tokoh iko 


\section{Karakter Pendukung}

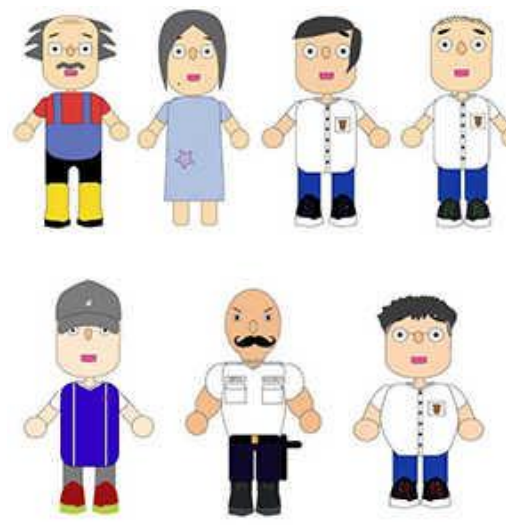

Gambar 2. Karakter Tokoh Pendukung

Karakter pendukung mempunyai ciri khas masing-masing. Penggambaran bentuk karakter tokoh pendukung dapat dilihat pada gambar 2 .

\section{Membuat storyboard}

Dalam membuat storyboard sangat penting dilalukan karena bentuk frame by frame akan terlihat dengan jelas makna cerita dari animasi ini. Dalam pembuatan storyboard dapat disertakan keterangan dari pola pengambilan gambarnya, scene demi scene dalam pengadeganan dalam diciptakan sesuai karakter masing-masing objek dan tipe pengambilan gambar dengan kamera juga bisa diciptakan.

Sketsa gambar storyboard untuk menjadi acuhan visualisasi dari pergerakan yang akan dibuat. (Dhimas, 2013).

\section{Produksi}

Langkah awal yang dilakukan yakni membuat desain karakter tokoh animasi secara manual setelah itu di scan. Untuk software editnya memakai Adobe Photoshop digunakan untuk membuat ketebalan garis karakter. Gambar yang sudah diedit dalam photoshop dipindahkan ke dalam aplikasi macromedia flash. Berikutnya rubah dari bitmap jadi vector dengan metode seleksi modify, bitmap, trace bitmap, hingga secara otomatis berganti dari bitmap jadi vector. Langkah berikutnya merupakan mengedit dengan memisahkan part objek menjadi terpisah bagian, misalnya tangan, kepala, kaki, dan sebagainya. Langkah berikutnya merupakan mengconvert objek tersebut jadi objek graphic. Buat proses pewarnaan memakai tools fill color. Hasil dari proses pembuatan objek bisa dilihat pada gambar dibawah ini.
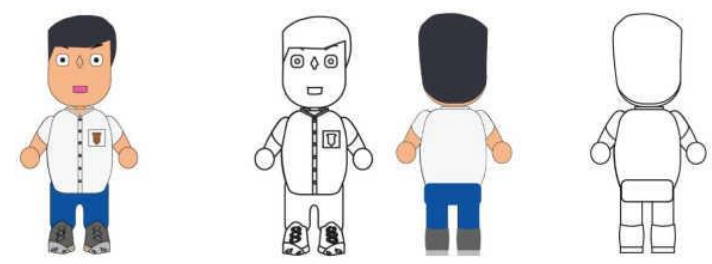

Gambar 3. Proses Pembuatan Objek Tokoh Utama

Hal dasar penganimasian gerak dilakukan per karakter, per objek dan latar belakang sesuai dengan jalan ceritanya. Langkah penganimasian dilakukan dengan menggunakan teknik movie clip, graphic, dan tweening (motion tween dan shape tween), frame by frame, dan lain-lain sesuai dengan kebutuhan. Film animasi ini diseting dengan keakurasian resolusi 640 pixel x 480 pixel dan ukuran standar yang digunakan antar frame adalah 24 frame per second (24 fps). (Hendratman, 2008).

Tweening animation digunakan buat proses pembuatan objek pemain utama dengan membuat objek animasi secara manual setelah itu dicoba proses scanner buat memindahkan objek tersebut dari wujud manual menjadi digital. Buat memakainya didalam flash, dicoba proses trace dari objek berupa bitmap menjadi vector serta pemberian pewarnaan pada objek tokoh tersebut. Langkah terakhir merupakan mengconvert objek tersebut jadi simbol yang berupa graphic. Desain karakter yang telah terbuat dipotong pada bagian-bagian tertentu serta ditaruh di dalam library, sehingga bentuk bagian potongan dari desain yang hendak digunakan tinggal mengambil dari library saja. Tampilannya bisa dilihat dibawah ini. Memakai keyframe yaitu untuk mengunci perframe dimana keyframe ini berfungsi untuk menandakan pergerakan dari mana sampai mana. Selain itu dengan adanya keyframe ini seperti memberikan batasan antar pergerakan untuk tidak menubruk satu dengan yang lainnya. Keyframe juga seperti tanda kapan pergerakan itu muncul dan tidak. Dan apabila dalam 2 frame terdapat keyframe yang sama. Jika salah satu frame di ubah bentuk gambar 
atau lokasi gambarnya, maka frame satunya yang tidak diubah tidak akan berubah gambarnya.

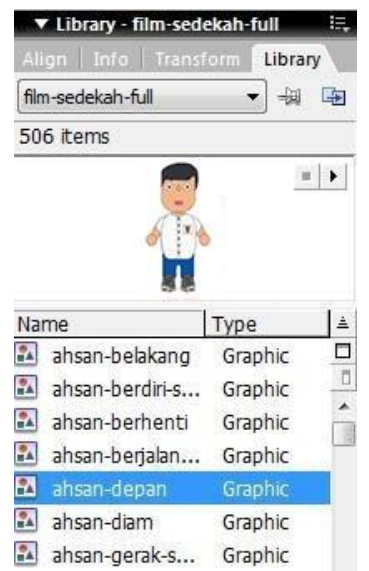

Gambar 4. Library dalam Flash

Langka awal yang dilakukan adalah membuat objek sesuai dengan naskah, kemudian mengkonvert objek yang dibuat menjadi movie clip dengan menggunakan menu yaitu Convert to Symbol. Rubah naa filenya menjadi "pembuka" dan pilih Type Movie Clip seperti pada gambar 5.

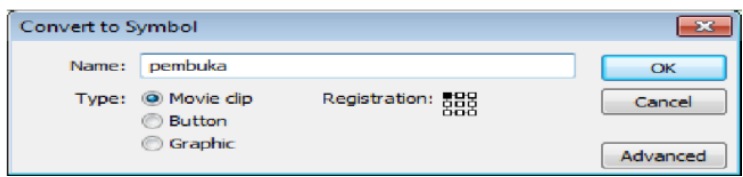

Gambar 5. cara membuat movie clip

Pergantian warna, pergantian bentuk objek ataupun bentuk lainnya dapat menggunakan teknik shape tween sehingga akan membentuk tanda panah dari arah kiri ke kanan, sedangkan untuk proses pergerakan maupun perpindahan objek digunakan pemanfaatan teknik motion tween. Pemilihan dari frame by frame untuk frame terakhir dan tuliskan Action script (F9) “_root.gotoAndPlay (" nama frame");" yang artinya menuju ke frame berikutnya, sedangkan dalam setiap movie clip yang berada pada pada timeline scene 1, diakhiri dengan Actions Script yaitu "stop()". Tujuan ini digunakan untuk menyelesaikan frame yang telah ditentukan ketika melakukan proses debbuging. Berikut adalah potongan-potongan adegan tiap movie clip:

Konsep latar yang dibuat yaitu latar pedesaan yang asri dan berada dekat gunung dan pesawahan yang terbentang luas. Adapula latar sekolah di desa tersebut. Dan latar daerah pertokoan yang salah satu tokonya merupakan toko sepatu.

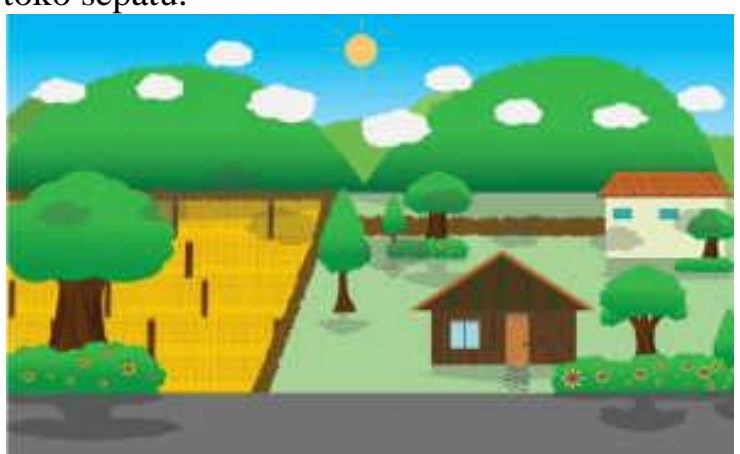

Gambar 6. Background Pedesaan

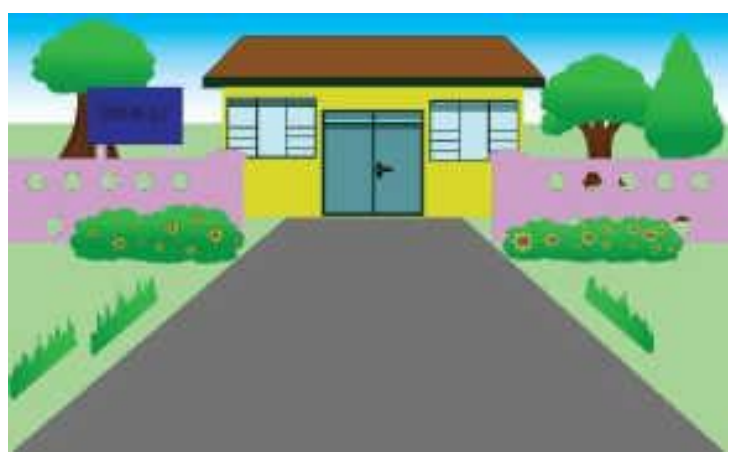

Gambar 7. Sekolah iKo

\section{Pasca Produksi \\ Pengisian Suara}

Suara tokoh dalam film animasi pendek ini dicoba dengan metode merekam suara orang dengan perlengkapan bantu perekam yang menciptakan suara dengan format. amr, setelah itu hasil rekaman tersebut diconvert dalam format. mp3 dengan dorongan aplikasi Cool Record Edit Pro. Penggunaan format audio mp3 ini mengacu kepada media yang akan digunakan untuk publikasi.

Setelah proses convert berakhir, edit mengunakan aplikasi Cool Record Edit Pro. Pengeditan ini dicoba buat melenyapkan suarasuara yang tidak dibutuhkan ataupun noise pada suara. Tampilan saat sebelum serta setelah proses pengeditan suara bisa dilihat dibawah ini.

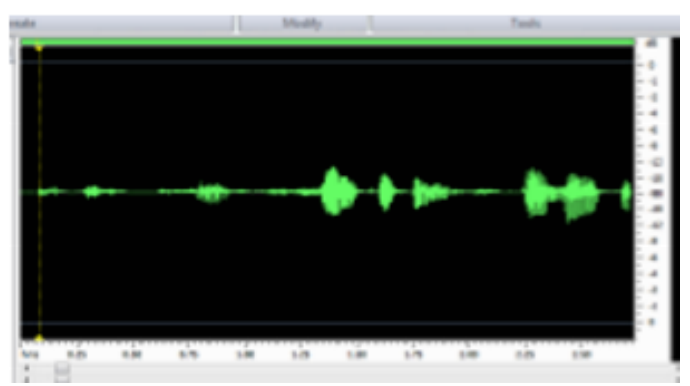

Gambar 8. Proses pengeditan suara 
Fasilitas untuk memasangkan audio pada film ialah buka layer baru pada movie clip yang hendak dipasangkan audio. Setelah itu klik layer yang hendak digunakan buat penempatan audio, serta tarik audio dari library serta letakkan pada layer yang ada. (Benjamin Gorton, 2008).

\section{Rendering}

Proses rendering dicoba dengan menu Moyea Swf To Video Converter Pro. Moyea Swf To Video Converter Pro digunakan untuk menyatukan movie dengan suara dubber ataupun backsound jadi satu, hasil rendering (output) ini telah berformat avi. Lalu file .swf tercipta hingga convert movie .swf memakai aplikasi Moyea Swf To Video Converter Pro dengan menginputkan file dengan metode browse-from folder serta cari dimana file terletak.

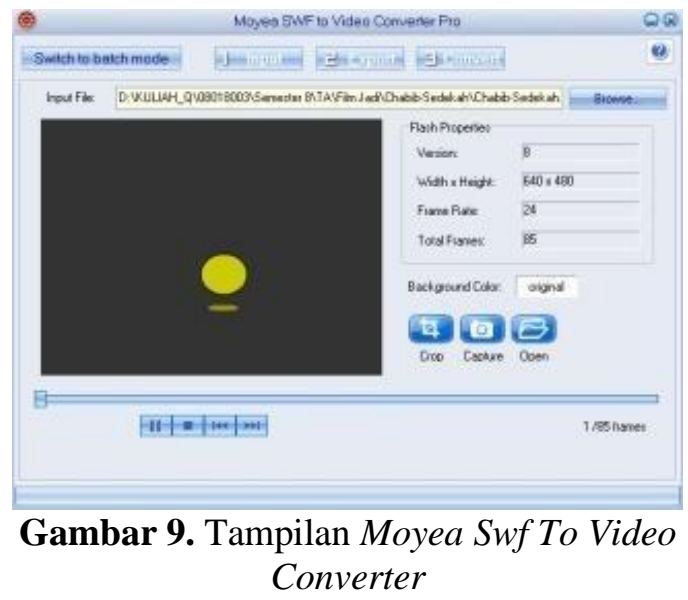

Secara otomatis pada saat file akan di inputkan, pada file properties hendak langsung tercantum tipe flash yang digunakan dengan resolusi standar 640 x 480 , frame rate $24 \mathrm{fps}$ serta total frames mencapai 85 frame. Sesi berikutnya tekan tombol export seperti gambar diatas.

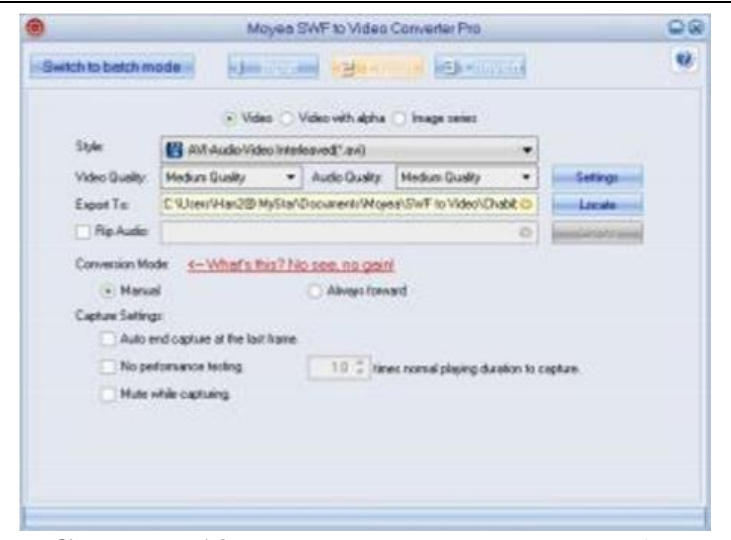

Gambar 10. Export Moyea Swf To Video Converter

Berikutnya seleksi file dari format AVI, video serta audio quality diset menjadi medium quality, serta langsung ke menu Export to. Sesi terakhir merupakan memilih tombol convert, hingga secara otomatis file dari format .swf akan berganti menjadi format .avi seperti yang dijelaskan pada gambar 24. Sesi terakhir, klik convert play and capture, akhir perintah dengan klik finish yakinkan seluruh frame sudah tercapture. (MADCOMS, 2013).

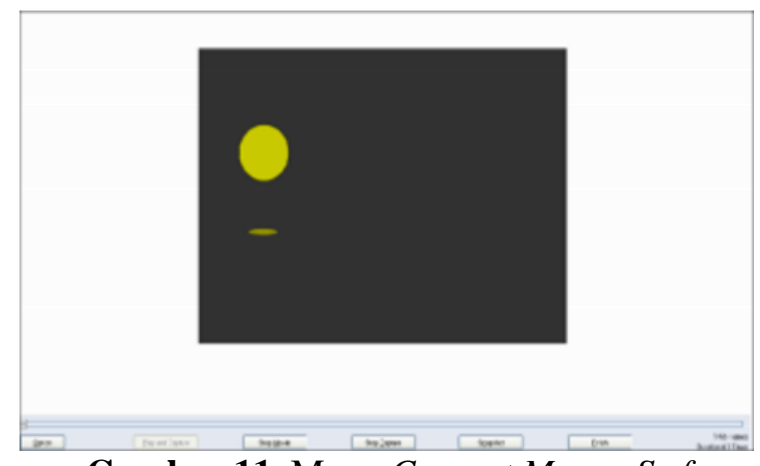

Gambar 11. Menu Convert Moyea Swf

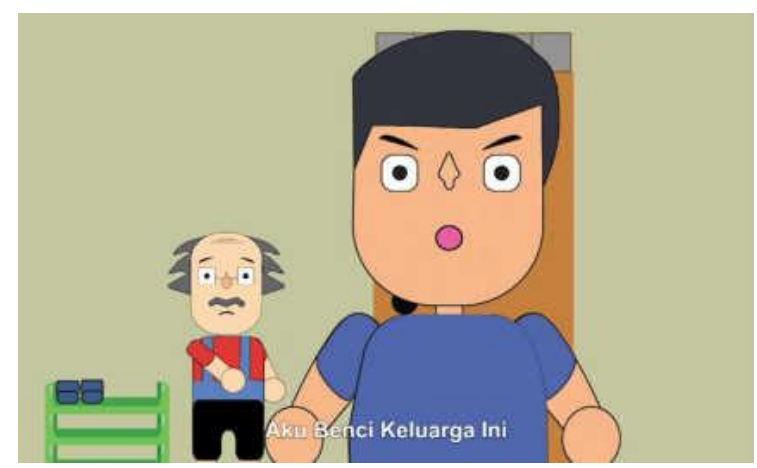

Gambar 11. Adegan dalam Film 


\section{KESIMPULAN}

Film animasi sendiri sudah banyak ditayangan di televisi sebagai media hiburan dan digemari oleh anak-anak. Hal ini yang membuat penulis berkeinginan membuat sebuah program yang berisikan film animasi yang bukan hanya sekedar memberi hiburan, namun juga memiliki pesan yang secara tidak langsung dapat mengedukasi penonton.

Untuk memproduksi sebuah film animasi, dibutuhkan ketekunan dan ketelitian agar memperoleh sebuah pergerakan karakter yang berjalan secara halus selayaknya manusia pada umumnya. Dan film yang dihasilkan tidak membosankan karena target utama dari film animasi adalah anak-anak. Namun tidak menutup kemungkinan ditonton oleh orang dewasa. Selain animator harus teliti dalam membuat pergerakan setiap karakter agar pergerakan terlihat tidak patah, tidak saling berbenturan, dan juga animator harus memperhatikan penempatan layer pada aplikasi pembuatan pergerakan agar tiap karakternya berada diposisi yang tepat. Film animasi yang baik bukan hanya sekedar lucu untuk hiburan. Namun harus ada pesan yang tersampaikan dari cerita ya dianimasikan tersebut. Pengembangan ide harus dibuat sekreatif mungkin, persiapan gambar harus dibuat sematang mungkin agar pada saat pengerjaan pergerakan lebih mudah dan tidak berantakan. Dalam memproduksi film animasi juga harus terjadwal dan pengerjaannya pun harus memiliki target waktu pencapaian. Agar hasil yang dicapai sesuai dengan keinginan dan tidak berantakan dalam pengerjaanya.

Berdasarkan hasil penelitian dan pembahasan, maka dapat disimpulkan hal-hal sebagai berikut :

Pesan moral yang terdapat didalam film animasi "Si Iko episode Penyesalan" dapat tersampaikan dengan baik karena bahasanya yang simpel dan mudah dimengerti.

Film animasi yang dihasilkan layak untuk dipertontonkan kepada anak-anak terutama anak usia 2-8 tahun karena mengandung nilai edutaiment baik secara moral maupun religious serta dapat menghibur anak-anak.

Film animasi merupakan alat bantu pembelajaran yang digunakan oleh guru maupun orang tua dalam memberikan variasi pengajaran sehingga dapat memotivasi anak untuk belajar karena belajar menjadi menyenangkan karena adanya unsur hiburan.
Anak ingin selalu memberikan bantuan kepada temannya yang membutuhkan dengan cara bersedekah agar dapat meringankan beban penderitaan orang lain dan mendapat imbalan dari Allah SWT.

\section{REFERENSI}

Bekti Wulansari. (2019). Cara Mudah Membuat MEDIA PEMBELAJARAN Menggunakan Adobe Flash Professional CS6. Gava Media.

Benjamin Gorton. (2008). Adobe AIR Bible. KOTAKOM.

Darwanto Sastro. (2005). Televisi Sebagai Media Pendidikan Agama. Duta Wacana.

Dhimas, A. (2013). Cara Mudah Merancang Storyboard Untuk Animasi Keren. Taka Publisher.

Dwi Susanti. (2009). Strategi Pencegahan Perilaku Negatif pada Anak-anak Sebagai Akibat Tayangan Televisi dan Model Tayangan Edukatif untuk Anak-anak. UPN Veteran.

Hendratman, H. (2008). The Magic of 3D Studio Max. Informatika.

Herliyani, E. (2014). Animasi Dua Dimensi (p. 8). Graha Ilmu.

Iwan Binanto. (2010). Multimedia Digital Dasar Teori dan Pengembangannya . Andi Offset.

MADCOMS. (2013). Adobe Flash Professional CS6. Andi Publisher.

Nurjanah. (2009). Implementasi Tweening Animation. Universitas Ahmad Dahlan.

Ruslan, A. (2016). Perkembangan dan Konsep Animasi. Ghalia Indonesia.

Subakti. (2008). Awas Tayangan Televisi. Elek Media Komputindo.

Widagdo, M. B. \& G. s. W. (2007). Bikin Film Indie Itu Mudah! Andi Offset.

Yoko Gerihandito. (2006). Teknik Tweening Dalam Pembuatan Film kartun "Kod Dok." Universitas Ahmad Dahlan.

\section{PROFIL PENULIS}

Supriyadi merupakan staff pengajar pada Universitas Nusa Mandiri. Untuk bidang tulis menulis, selain buku Broadcasting Televisi Teori \& Praktik, sebelumnya ia juga aktif menulis artikel di BSI NewsLetter, Majalah SDA Asia dan Broadcast Magz. Antara komputer dan broadcasting inilah yang membuatnya menjadi tenaga pengajar yang mumpuni tanpa melupakan latar belakang di 
Journal Komunikasi, Vol 12 No.2 September 2021

P-ISSN 2086-6178 E-ISSN 2579-3292

bidang komputer. Untuk beberapa tulisannya bisa dilihat pada web pribadinya di http://pojokspy.blogspot.com dimana banyak mahasiswa yang tertarik dan menerapkan materi perkuliahan yang didapat pada blog tersebut. Selain itu juga sebagai Asesor Bidang Media Kreatif dengan pembidangan Videographer dibawah naungan LSP InsCinema. 